2021-07-23

\title{
The dental therapist's role in a 'shared care' approach to optimise clinical outcomes
}

\section{Sadura, Z}

http://hdl.handle.net/10026.1/17597

\subsection{8/s41415-021-3233-3}

British Dental Journal (BDJ)

Springer Nature [academic journals on nature.com]

All content in PEARL is protected by copyright law. Author manuscripts are made available in accordance with publisher policies. Please cite only the published version using the details provided on the item record or document. In the absence of an open licence (e.g. Creative Commons), permissions for further reuse of content should be sought from the publisher or author. 


\begin{abstract}
Introduction

Dental therapists have a key role to play in the provision of dentistry in the UK. The Dental Workforce Advisory Group has reported this is relevant in multiple areas, including prevention and care in young children, and to support dentists in providing advanced and routine treatment for complex adult patients within the wider collaborative dental team. There remain diverse and multiple barriers and challenges to utilising the optimal scope of the dental therapist in general practice. In 2013, the General Dental Council introduced direct access (DA) legislation in the UK. By utilising the potential of dental therapists, some of the above challenges could be overcome and the DA approach optimised.
\end{abstract}

Aims The purpose of this article through presenting clinical cases is to demonstrate the full scope of practice of the dental therapist and highlight how clinical outcomes can be optimised for patients when a 'shared care' approach is followed.

Conclusions Notwithstanding the complexities of the financial implications practice owners face, through knowledge and understanding of the role and scope of the dental therapist within the wider dental team, optimal treatment of dental patients in the UK can be encouraged.

[381 words] 


\section{Introduction}

Dental therapy training was first introduced in early 1960's, in New Cross South East London Hospital. The school was shut in 1983 but had trained 60 Dental Therapy students each year. Following this closure, a second school, (but much smaller with only 8 students per cohort), was developed in Whitechapel, London (today this is Queen Mary University, QMUL). ${ }^{1}$

Dental therapy training was introduced as a method of providing clinicians who could bridge the shortfall of professionals in what was called the 'school dental services'. For many years, a Dental Therapist could only work within these community services or hospital settings, unlike a Dental Hygienist who was able to work in general practice. ${ }^{1,2}$ By 2002 , the profession was changing and employment of Dental Therapists expanded across all sectors of dentistry. In the same year, the scope of practice for both Dental Therapists and Dental Hygienists were expanded and remain fairly unchanged to the current day. ${ }^{3,4}$

A 2013 report on workforce planning in the UK revealed "undeniably some degree of shortfall in dental workforce supply in the short term and under-utilisation of dental care professionals, both hygiene/therapists and clinical dental technicians". ${ }^{5 \mathrm{p} 105}$ The increasing size and complexity of treatment needs in the ageing population; the need to ensure preventive care is available from an early age; and an appropriate workforce to support the 'starting well, keeping well, maintaining well and sustaining well' approach of the Dental Workforce Advisory Group (DWAG) ${ }^{6}$ all impact on future workforce planning challenges. HEE's 2018 'Advancing Dental Care: Education and Training Review' suggests that currently, the absolute numbers of Dental Therapists required relative to the different areas of the profession is unknown and that training needs to remain flexible to be able to accommodate changes. ${ }^{7}$ The 2019 DWAG states that there will be a need for an "increase in DCP student numbers, ensuring their training is integrated with dental students in preparation for effective team working and meeting the needs of all sections of the population". ${ }^{\mathrm{p} 7}$ 
Adopting a team approach to patient care will be key, and the UK Department of Health and British Dental Association have both emphasised the importance of the skill-mix of the dental team". ${ }^{4} \mathrm{~A}$ study exploring the views of GDPs in West Sussex concluded that, "in general dentists had a favourable attitude towards dental therapists, although there was a real lack of knowledge about their permitted duties" ${ }^{3 \mathrm{p} 41}$. Most dentists felt therapists should treat children and adults with special needs.

Providing care by Dental Therapists in UK practice is complex for multiple reasons including factors relating to the current NHS contract and remuneration of Therapists. ${ }^{6}$ The risk of underutilisation of Dental Therapists is that it can lead to frustration amongst therapists, who consequently feel undervalued and may eventually lose the confidence to pursue the therapy aspect of their role. ${ }^{4}$ Financial factors aside, reasons for the under-utilisation of Dental Therapists in dental practice have been reported by the GDC to be related to a variety of issues including educational challenges, policy and unintended or negative reaction to policy, referral barriers and practical challenges in the sharing of care. ${ }^{8}$ It has also been shown that patients' acceptance of therapists follows dentists' acceptance, and so it seems likely that if dentists are supported to accept and understand the full utilisation of therapists, patients are also more likely to agree. ${ }^{3}$

In 2013, along with the Scope of Practice guidance, the GDC introduced Direct Access legislation in the UK. Direct Access aims to facilitate patients' access to care by allowing trained and competent Dental Care Professionals (DCPs) to diagnose, treatment plan and carry out treatments within their scope of practice ${ }^{9}$ without the patient needing to see a dentist first for a treatment prescription. ${ }^{10,11}$ There are numerous challenges to supporting the Direct Access (DA) approach, and facilitate optimal utilisation of the skills of Dental Therapists in practice, including educating dentists to recognise and appreciate the potential of the Dental Therapists within their teams. ${ }^{11}$ Evidence shows that dentists are aware of the importance of teamwork and value the support from the staff they have. Additionally, the majority of dentists are in favour of a team approach to care. ${ }^{3}$ The recent GDC 
review into the SoP reported that DCPs are more familiar with the SoP remit than dentists, and that Dental Nurses are the group least familiar with it. ${ }^{8}$

This would suggest that there is not a fundamental attitude problem toward integrating a team approach to dental care across systems, and that educating the whole dental team on the contemporary Scopes of Practice of their colleagues may begin to address some of these challenges. Changes to the system may also be advisable to support integration, but these are outwith the remit of this paper.

[Table 1 here]

Table 1 shows the scope of practice of Dental Therapists and Hygienists compared to dentists and the potential each has to complement the full dental team and care of patients in the UK. Education providers rely on the SoP document to inform course content, support and Fitness to Practise processes, and to develop and deliver professional development and training opportunities. Where Dental and Therapy students are trained together it is noted that they are more cognisant of one another's SoPs and delegation of appropriate duties and teamworking between the two professions is enhanced. ${ }^{12}$ It seems likely then that recently qualified graduates and education providers are in the best place to highlight and showcase the successful patient outcomes that can be achieved when different members of the team are working together in the optimal way, with each working to the full extent of their Scope. In 2013, the University of Plymouth Peninsula Dental School (PDS), introduced a curriculum that fully integrates the training of undergraduate Dental Therapists and Dentists from day one. This prepares them to understand the Scope of the other, collaborate during their course and after dental school in the workplace, as well as preparing Therapists for Direct Access. ${ }^{12}$

The aim of this paper is to present undergraduate student clinical cases that exhibit teamwork, shared care and the optimal use of both to achieve successful patient outcomes. 


\section{Clinical Case Studies}

Two clinical cases were prepared by an undergraduate Dental Therapist for their final year assessments. Each of these demonstrated a range of treatments that can be undertaken by an appropriately trained, competent, and indemnified therapist within their SoP. They also showcase how a shared care teamwork approach between a Dental Therapist and Dentist can provide excellent treatment outcomes for the patient.

All cases were assessed initially and treated within scope by the Therapist under Direct Access legislation, and utilising appropriate group directives where necessary. The therapist undertook the initial examination, with screenings and special tests including periodontal charting, indices and radiographs. Radiographs were interpreted by the therapist initially and subsequently reported by the dentist. Although there was no prescription from the dentist for the therapist's treatment stages of periodontal care, disease stabilisation and direct restorations; the shared care required active participation of both parties in collaborative planning, discussion and co-ordinated treatment delivery from the beginning to ensure that the work was complementary and not contradictory. This included the areas of restorations impacting denture design and endodontic treatment; and the timing and placement of restorations with periodontal care. Such a shared care approach between therapist and dentist proved to provide treatment outcomes for the patient that they deemed successful. In this way the patient's treatment time was reduced because treatments could be synchronised and co-ordinated, and the patient did not have to wait so long for appointments. In private practice this may also reduce the overall cost to the patient.

Figures 1-5 are examples of two shared care cases completed by Undergraduate Dental Therapy and Dental students.

Figures 1 and 2 show the first case that combined the therapist's periodontal care shared with extractions and a partial denture by the dental student. Figures 3-5 demonstrate a wider remit for the therapist including direct restorations working alongside the dentist providing endodontic 
treatment. "After" images were taken at completion of treatment in scope of therapist, prior to completion of all final dental student work.

\section{Discussion}

Dental Therapy as a profession has altered considerably since the 1960 s when the first dental therapy school was set up. The most notable changes have been the 2002 scope of practice expansion, permission of Dental Therapists to be employed within all sectors of dentistry, and the creation of 'direct access' in 2013. Nevertheless, the role contains core skills that have remained unaffected throughout multiple other changes, as outlined in table 2.

A 2007 study described the proportion and volume of work undertaken in primary dental care that could be delegated to hygienists and therapists. Without Direct Access Dental Therapists could provide up to $35 \%$ of a patient's care, and with Direct Access this could rise to $70 \%$ of visits and $58 \%$ of clinical time. ${ }^{10}$ There is still opportunity to support a wider and more accurate recognition of the scope of Dental Therapists within the profession to overcome the existing barriers to full optimisation. Thorough knowledge and understanding of the Dental Therapists' scope across the full remit of GDC registrant categories would support better utilisation of the them within the field of dentistry, although it is acknowledged that this is only one part of a much picture with workforce, political, governance and financial issues all having additional impact. ${ }^{4-7,10,13}$

It is reported widely that an expansion in the dental workforce is required, and that therapists have an important role to play to meet the increased demand of patients' treatment needs associated with multiple factors including the ageing population. ${ }^{5-6,13}$ Undergraduate education has an important role to play in this regard. 7,12

\section{Conclusion}

By optimising full SoP of Dental Therapists we would allow dentists to focus on more complex items of treatment including crowns, bridges, endodontics, dentures and implants, which lie outside of the 
therapist's current scope of practice. Case studies demonstrate successful patient outcomes when a Dental Therapist is used to their full potential and a shared care approach is adopted.

Through embedding such integrated teaching in an undergraduate curriculum, which places great emphasis on a shared care approach, the potential for enhanced integration of Dental Therapists into the profession can be optimised. 
References:

1. Gibbons, D., Corrigan, M. \& Newton, J. 2000. The working practices and job satisfaction of dental therapists: findings of a national survey. Br Dent J 189, 435-438 https://doi.org/10.1038/sj.bdj.4800793

2. Stockley, J. 2009. Being a dental therapist. Vital, 6, 22-23. https://doi.org/10.1038/vital990

3. Gallagher, J. \& Wright, D. 2003. General dental practitioners' knowledge of and attitudes towards the employment of dental therapists in general practice. Br Dent J 194, 37-41. https://doi.org/10.1038/sj.bdj.4802411

4. Godson, J., Williams, S., Csikar, J., Bradley, S., \& Rowbotham, J. 2009. Dental therapy in the United Kingdom: part 2. A survey of reported working practices. Br Dent J 207, 417-423. https://doi.org/10.1038/sj.bdj.2009.962

5. Harper,P., Kleinman, E., Gallagher, J. \& Knight, V. 2013. Cost-effective workforce planning: optimising the dental team skill-mix for England. Journal of Enterprise Information Management, 26 (1/2), 91-108. https://doi.org/10.1108/17410391311289569

6. Dental Workforce Advisory Group for England. 2019. The Future Oral and Dental Workforce for England. Liberating human resources to serve the population across the life-course. Available at: https://www.hee.nhs.uk/sites/default/files/documents/FDWF\%20Report\%20\%207th\%20March\%202019.pdf. Accessed 28th June 2020

7. HEE. 2018. Advancing Dental Care: Education and Training Review Final report. Available at: https://www.hee.nhs.uk/sites/default/files/documents/Advancing\%20Dental\%20Care\%20Fi nal\%20Report\%20.pdf Accessed 28th June 2020

8. General Dental Council (2020). Scope of Practice Review: Final report. Available at: https://www.gdc-uk.org/about-us/what-we-do/research/research/detail/fitness-topractise/scope-of-practice-review Accessed 28th June 2020

9. General Dental Council (2013). Scope of Practice. London: General Dental Council 
10. Evans, C., Chestnutt, I. \& Chadwick, B. 2007. The potential for delegation of clinical care in general dental practice. Br Dent J 203, 695-699. https://doi.org/10.1038/bdj.2007.1111

11. Turner, S., Tripathee, S. \& MacGillivray, S. Direct access to DCPs: what are the potential risks and benefits? Br Dent J 215, 577-582 (2013). https://doi.org/10.1038/sj.bdj.2013.1145

12. Wanyonyi, K., Radford, D. \& Gallagher, J. 2014. Dental skill mix: a cross-sectional analysis of delegation practices between dental and dental hygiene-therapy students involved in team training in the South of England. Human Resources for Health 12, 65-73.

https://doi.org/10.1186/1478-4491-12-65

13. Gallagher, J. \& Wilson, N. 2009. The future dental workforce? Br Dent J 206, 195-199. https://doi.org/10.1038/sj.bdj.2009.114 